\title{
Consideraciones en torno al proceso de resimbolización en los márgenes de la estética reciente*
}

\author{
A view on the process of resymbolization in the contemporary aesthetics \\ GuILlermo AguirRE** \\ Universidad de Deusto/Universidad Complutense de Madrid, guillermo.a.m@ucm.es \\ Recibido el 12 de agosto de 2020, Aprobado el 25 de noviembre 2020
}

\begin{abstract}
Resumen Abstract
Partimos de la sustitución histórica de una cosmovisión trascendente, cuyo símbolo mayor es la cruz, por otra inmanente que encuentra en la esfera su imagen de totalidad. El objetivo de estas páginas consiste en presentar, con el ejemplo de modelos estéticos, el sentido latente de esta traslación. Metodológicamente, nos apoyaremos en fundamentos hermenéuticos relativos a la función del símbolo. La conclusión de nuestro estudio es que, tras un periodo de proliferación de perspectivismos y de necesaria relativización, actualmente asistimos a un momento de reorganización simbólica por vía de un monismo-trascendental.

This paper is focused on the substitution of a transcendental view of the world, whose axial symbol is the cross, for an immanent one, whose symbol is the sphere. The goal of these pages is to expose, with the help of aesthetics models, the hidden meaning of this movement. In relation with the methodology, we will find help in hermeneutic foundations pertaining to the function of the symbol. We conclude that, after a time of necessary relativism and the proliferation of perspectivisms, emerges today a new stage of symbolic reorganization by means of a transcendental monism.
\end{abstract}

\section{Palabras Clave Keywords}

Resimbolización, cruz, esfera, Resymbolization, Cross, Sphere, trascendencia, inmanencia.

Transcendence, Immanence.

\footnotetext{
* La realización de este artículo ha sido financiada con un Contrato Juan de la Cierva - Incorporación, concedido por el Ministerio de Economía, Industria y Competitividad (JCI-2015-26934).

** Guillermo Aguirre es doctor en Estudios interculturales y Literarios por la Universidad Complutense de Madrid (2012). De entre sus publicaciones destacan los ensayos Forma y voluntad: un ensayo sobre la naturaleza de la abstracción, la civilización y la cultura como fenómenos dinámicos de conocimiento (Verbum, 2015), y En el vientre de la tierra. Una lectura de El caballo de Turín, de Béla Tarr (Devenir), de inminente aparición. Es miembro colaborador del proyecto "POEMAS: POEsía para MÁS gente. La poesía española en la música popular actual", dentro de la convocatoria de Proyectos de I+D de Generación de Conocimiento (referencia PGC2018-099641-A-I00). Duración del proyecto: 2019-2021.

○ orcid.org/0000-0001-7331-7947 Google Scholar
} 


\title{
Introducción
}

Con el siguiente estudio se pretende realizar un somero recorrido en torno a la significativa traslación de la cruz a la esfera como símbolos de totalidad en Occidente. Esta deriva encuentra su reflejo y se formaliza en las artes, en la medida en que expresan explícitamente el proceso que lleva de un orden orientado a lo trascendente a uno en el que el sujeto se entroniza a sí mismo como sui generis divinidad. ${ }^{1}$ Se reflexionará, en este sentido, en torno al curso tomado por la estética occidental a lo largo del pasado siglo en lo relativo a cuestiones nucleares tales como el decaimiento de un ordenamiento simbólico, la paulatina y tambaleante formalización de uno nuevo, y la incidencia de este hecho en el sentido condensado en la obra de arte.

\begin{abstract}
Nos situamos a finales del siglo XIX, momento en que un concreto espectro simbólico se desmorona a raíz del colapso derivado del proceso de secularización comenzado en el Barroco o incluso algo antes. ${ }^{2}$ En lo relativo a este acontecer, parece conveniente reparar en el hecho de que, a raíz de este momento crítico se advierte un salto cualitativo en la producción de símbolos axiales esquemáticos,
\end{abstract}

\footnotetext{
${ }^{1}$ John Gray comprende el ultraliberalismo actual como una deriva más del monoteísmo, si bien en un momento en el que el sujeto se ve guiado por la idea de su propia divinización dentro de un estado que identifica con las ya afamadas palabras de "sentimental religion of humanity" (92). Este estado común, espoleado por la economía presente, encuentra sus proyecciones en todas las parcelas de realidad, desde la teología -la Iglesia se queja de un creciente neognosticismo secular- hasta la filosofía -Skolimowski hablará en La mente participativa (2016) de un sujeto que es copartícipe de la creación. Entre un sinnúmero de ideas afines al respecto expuestas por el filósofo polaco, leemos: "Aun cuando la divinidad se conciba como causa primera, es necesaria la mente participativa para descubrir y actualizar su naturaleza" (461)-, pasando, por supuesto, por las artes, cuyo estado de hipertrofia, en lo relativo al aspecto que nos concierne, lo podemos encontrar en el arte posthumanista, desde cuyos presupuestos exponen sus obras nombres consagrados como Eduardo Kac y Stelarc.

${ }^{2}$ Encontramos en un interesante artículo de Sigmund Méndez los siguientes comentarios relativos a este proceso en el que la consolidación de lo alegórico converge con una evidente fragmentación simbólica: "Mirando específicamente el ámbito central del siglo XVII, con sus antecedentes y prolongaciones en el XVI y el XVIII, el Barroco marca el momento de una crisis medular del sistema hegemónico y está conformado por un conjunto de controles estratégicos e impulsos disgregantes -plasmados en la polaridad matemática de diferenciación e integración, y en la musical de consonancia y disonancia- que, al interior de ese horizonte, atraviesan desde la base hasta la punta de la pirámide social e ideológica en una dialéctica donde, por un lado, sus diferentes componentes son sometidos a un todo unificador que se afirma en tanto que se desdibuja, y, por el otro, las partes asumen o construyen su propia posibilidad de espacios vitales y expresivos -encontrándolos, a veces, sólo en las fracturas- dentro de un marco general de sentido" (Méndez 149). Más adelante, y a partir de las reflexiones de Rodríguez de la Flor, hablará de una escenificación de la propia decadencia.
} 


\begin{abstract}
presentados estéticamente desde su total desnudez. ${ }^{3}$ Así, la exposición austera de formas elementales como el punto, el círculo, la cruz, etc., ${ }^{4}$ sin ornato o adherencia alguna, se acentúa en grado tal que hemos de remontarnos a una fase avanzada del Neolítico para observar un fenómeno semejante -sin que al hacer referencia a este último periodo pueda hablarse de una cronología exacta, teniendo en cuenta que se presenta temporalmente disperso pues, ante todo, denota la consecución de un grado determinado de civilización-. ${ }^{5}$
\end{abstract}

\title{
Resimbolización en la estética reciente
}

Una serie de símbolos esquemáticos expuestos de modo masivo relativos a una incipiente comprensión del mundo desde parámetros conceptuales da paso, en el curso que separa el periodo megalítico de aquél que Jaspers (2017) denomina Era axial, a un tejido simbólico-conceptual, en este caso, altamente articulado y desarrollado. Se trata de un curso que en Occidente participará de una orientación trascendente y que, con el auge del cristianismo, encontrará en la cruz su símbolo dominante. ${ }^{6} \mathrm{El}$

\footnotetext{
${ }^{3}$ Trías, en La edad del espíritu, habla de un "retorno a la unión" (23) una vez que el símbolo axial de una época -con sus distintas proyecciones- ha quedado fragmentado, inútil. En este acudir a un estado original se advierte una primera intención de volver a fundamentar la realidad sobre una imagen nuclear. Todo ello se observa por medio de objetos estéticos reducidos a su grado cero de significación, estado de concentración máxima -casi asimbólico- desde el que el artista -y su obra con él- rechaza adherencias indeseables, exponiendo con ello un ensimismado estar desde la mera materialidad.

${ }^{4}$ Este fenómeno, relativo a la expresión de objetos desnudos y ajenos aún a los sedimentos con los que los irá enriqueciendo -o, para quien así lo desee ver, adulterando- cada cultura, atañe asimismo a algunas otras manifestaciones elementales tales como el color, el ritmo o la numerología, objetos comunes sobre los que, tal y como ocurre con las figuras geométricas, se irá dando forma y consistencia a un panteón de motivos y dioses ramificado en su apariencia externa en función de una u otra cultura.

${ }^{5}$ Engarzando la idea de una proliferación de símbolos axiales -espacios u objetos llamados a vincular un orden telúrico con otro inmanente y con uno trascendente-, encontramos que esta necesidad de hallazgo de un centro y, en consecuencia, de establecimiento de coordenadas, esto es, de organización de un espacio inmensurable, encuentra su proyección tanto en la verticalidad del eje telúrico-fenoménico-trascendente, como en una horizontalidad relativa a un orden histórico. La cruz acumula ya en la prehistoria un alto valor simbólico. Recogemos al respecto a las palabras de Ina Wunn: “Durante el Neolítico la estrella polar no existía, y tampoco se puede averiguar la posición meridional del sol a mediodía sin la ayuda de, por ejemplo, la medición del tiempo. Por esa razón, la averiguación de los puntos cardinales tuvo que haberse producido ya en la Prehistoria mediante un procedimiento que en la etnología se conoce como Círculo Índico y cuya propagación mundial permite deducir su considerable antigüedad" (331). Esta cruz conformada por los puntos cardinales irá derivando -si bien sus orígenes quedan desconocidos- hacia grados más complejos de significación.

${ }^{6}$ Nos desplazamos ya, en fin, si bien evidentemente no entraremos en ello, en el uso político de esta imagen universal de origen prehistórico observable en las diferentes culturas. Un testimonio de su universalidad, sintomático en cualquier caso de su rol preponderante, lo encontramos en la tradicional división de las ciudades antiguas en cuatro cuadrantes -en ocasiones cada uno de ellos
} 


\begin{abstract}
presente esquema teológico-político alcanzará en el Barroco ${ }^{7}$-ya al abrigo de un catolicismo detalladamente codificado- y bajo la aludida imagen de la cruz, su época de esplendor, al tiempo que de incipiente decadencia mantenida hasta finales del siglo XIX -momento en que, más que de decadencia, es preciso hablar de la evidencia de una pérdida de función de dicha imago mundi dado que el conjunto de aspectos sobre los que se apoyaba quedan despojados de vigor. Hacemos, con esto último, alusión a un sentido histórico-teleológico, a un transcendentalismo aunado a dicho sentido, así como a una Iglesia ahora dañada no tanto en sus cimientos esenciales, que la trascienden, sino en su aparato dogmático-. . $^{\circ}$
\end{abstract}

\begin{abstract}
poseedor de su propio templo asociado con una concreta divinidad (así en el caso de los incas)-. Desde el nacimiento de la ciudad -grosso modo-, desde el asentamiento altamente organizado en el Neolítico, y conforme a las facilidades que esta disposición concede a la hora de ser gobernada, resulta natural esta espacialización con sus muchas variantes ya desde épocas remotas. En otro orden de cosas, cabe añadir que, en contrapartida a la disposición rectangular, una organización circular remite a un ordenamiento diferente tanto en lo tocante a aspectos prácticos como políticoteológicos. Invitamos al lector al estudio de las obras de Lewis Mumford, al trabajo de Delfante Gran historia de la ciudad, a la Historia de la forma urbana de Morris y, en lo tocante al vínculo entre ciudad ideal y ciudad humana, a la obra de Rosenau La ciudad ideal, así como a algunas de las páginas de Ciudades y edificios, de Steen Eiler Rasmussen. La ciudad como mesocosmos entre el orden humano y el divino es un lugar común de la teología-política y en su idealización exagerada deriva en utopías, por lo común, devenidas en distopías. Regresando a la cruz cristiana de la que partíamos, y aun suponiendo que el proceso de simbolización es una acción incontrolable por el sujeto, encontramos en Pablo de Tarso al artífice de la construcción de una teología política fundamentada sobre la cruz y la figura de Cristo. La concentración de este símbolo alcanzará en el Barroco su mayor densidad, hasta el punto de escenificar su propia significación. Con esto, sobra añadir, cabe comprender que el grado de paroxismo de una entidad simbólica acaba por tornarla en imagen alegórica -se vuelve dramática, se falsea, se torna en simulacro, por tomar la expresión de Baudrillard-, pierde su carácter dinámico y, en suma, lo sacro se desacraliza.

${ }^{7}$ Seguimos leyendo en el trabajo de Méndez algunas de sus sugerentes valoraciones al respecto: "El Barroco es una alegoría histórica de la alegoría porque representa la tenaz reclusión de lo vertical en la interioridad, donde lo trascendente espiritual y su posibilidad de manifestarse se ven confinados al foso escondido de la conciencia. La esfera del Barroco es el alma como escenario plegado de la pugna y escisión del espíritu y el cuerpo; por ello, la materia en él es, sobre todo, anímica, la región aérea entre lo pneumático y lo telúrico en que se suscita el drama del hombre [nótese aquí la huella heredada, ante todo, de la mencionada teología política de Pablo]. Y su arte es medularmente paradójico, tejido aparencial, pero apariencia, como ha sugerido Dubois (1993), 'profunda', donde el teatro del mundo está referido a la conciencia que lo justifica y le da soporte. Cada entidad material se vuelve en el Barroco -al menos potencialmente- psicológica, y por ello se eleva su posibilidad diciente como discurso interior, siempre alterno y mediador, transido por una bidireccionalidad alegórica. Pero los sistemas metafísicos como el de Leibniz despliegan una alegoricidad sólo como sintaxis abstracta de un código arbitrario (se acercan más a ser, sí, una signatura que un symbolon); no, según fue en la teología cristiana, como un conjunto de significados onto-teológicamente determinados en cada ente, en el tejido revelado de un lenguaje necesario. El atomismo espiritual de Leibniz, pese a estar sustentado en la continuidad (natura non facit saltus) y en el principio especular universal de los neoplatónicos de la Unidad absoluta (omnia ubique), sugiere un conjunto abstracto de individualidades herméticas que refleja ya, desde el ámbito de la metafísica, la segmentación clausurada de las subjetividades en la inmanencia y la diáspora del Ser, continuamente reclamado y refundado como precaria isla de un archipiélago ideal, cuya dispersión es apenas contenida, o disimulada, por el principio de la Mónada-Mar absoluta." (Méndez 162-163). ${ }^{8} \mathrm{~A}$ modo de natural negativo del momento en que se comienzan a adherir significaciones sobre
\end{abstract}


Llevando todo ello al terreno de las manifestaciones estéticas, observamos que en esos comienzos del siglo XX las artes se van a abocar a una infatigable poda tendente a rechazar toda adherencia superpuesta sobre las formas esquemáticas. Desde esta deriva podemos advertir la sustitución masiva de símbolos de orientación trascendental por símbolos vinculados con una cosmovisión inmanente, tales como el círculo, la piedra o aquellos otros que, en general, denotan el ensimismado cierre del tejido eidético.9 Este hecho, por otra parte, se solapa con la preponderancia del vacío como objeto compositivo, 10 ofreciéndose con ello una clave esencial relativa a una vía de renovación del imaginario. Dado que se trata de una materia abundantemente estudiada, baste con recordar, en lo que a nuestro ámbito de investigación se refiere y por nombrar ejemplos explícitos al respecto, los trabajos de Moore, Fontana, Oteiza, Judd, Serra, etc. El vacío, dicho sintéticamente, articula el par inmanencia-trascendencia por vía negativa.

En un orden próximo de cosas, y retomando lo atrás indicado, a la significativa alteridad entre un plano vertical-trascendente y uno

la cruz, de modo tal que el sujeto no busca ya un centro existencial, sino que, en la medida en que él mismo se ve a sí mismo como centro, rechaza el sentido que un eje simbólico externo le otorga. A ello podría añadírsele u oponérsele la idea de la innecesidad de búsqueda axial en un mundo -por resumir las múltiples variantes- ateleológico.

${ }_{9}^{9}$ Así por ejemplo, a la hora de hablar de las maternidades de uno de los creadores fundamentales del XX, en referencia a Henry Moore, Erich Neumann propone la siguiente significación: "He seeks to create an archetypal and essentially sacral art in a secularized age whose canon of highest values contains no deity, and the true purpose of his art is the incarnation of this deity in the world of today. This principle of incarnation lies at the root of all Moore's views on form, which he has expressed in his remarks on his work as a sculptor. Implicit in the mother-child motif is the whole of man's relation to the world, to nature, and to life itself. In the course of Moore's development the female reclining figure becomes more and more clearly archetype of the earth doddes, natural goddes, and life goddes. This is not to say that he 'knows' about these things, or that he sets out to create 'symbolic' figures as ordinarily understood. Only when the unwearying revolution about the feminine center becomes transparently clear in his work as a whole, and one sees how this center continually unfolds in the stadial development of his art, can one understand the essentially symbolic and archetypal nature of the deity to whose incarnation Moore's work is dedicated -one could even say 'consecrated'-" (17).

${ }^{10}$ Podemos acudir a las palabras de Oteiza en torno a la oquedad, para desde ellas abstraer su significado como espacio fundacional: "el cromlech vasco, es un pequeño cromlech interiormente vacío, construcción estética (estatua vacía) de protección espiritual, con el que finaliza el proceso artístico de nuestra prehistoria. Su relación con la evolución del euskera: así como la raíz piedra en la estructura de una palabra la sitúa en el paleolítico, la raíz que corresponde a vacío, hueco, redondo (que en el cromlech se definen) la situaría en el neolítico, testimonio que iría íntimamente unido al enriquecimiento del idioma con los conceptos metafísicos de independencia espiritual frente al mundo, del descubrimiento de la conciencia íntima y personal, de sentimientos de protección espiritual, de dominio, seguridad y libertad personales y de ampliación (duplicidad, polaridad) de términos o designaciones ya existentes" (135). De esta mixtura entre estética, ontología y nacionalismo, puede extraerse una idea interesante en relación con los vínculos entre trascendencia e inmanencia aquí tratados. 
Figura 1.

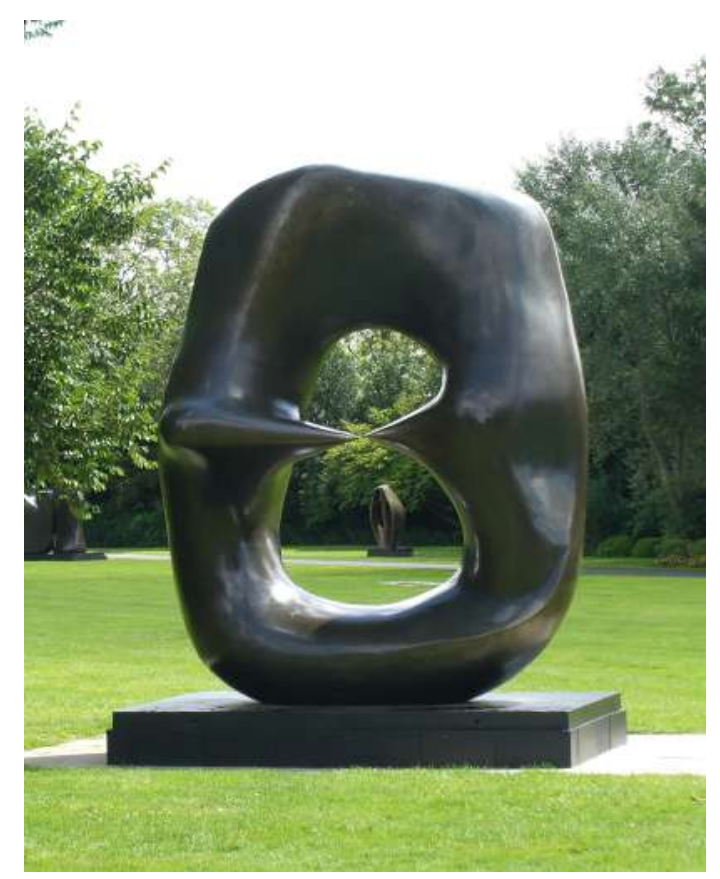

Moore, Henry. Oval with points, 1968. Bronce. Henry Moore Foundation. Perry Green. Hertfordshire.

sustancial, encontramos en El origen del mundo (1924), de Brancusi, un modelo explícito que encuentra su acomodo natural en el organicismo y el materialismo que prepara un posterior despertar simbólico. En este sentido, trabajos como los de Maria Martins o los de Jean Arp son explícitos en lo referente a estas búsquedas, sin dejar de lado la natural existencia de variantes de sentido opuesto como parte de lo que ha de comprenderse como un proceso sistémico. Esta misma intención de formatividad circular la advertimos, por citar algunos otros ejemplos tomados de diferentes expresiones estéticas, en la música de Scriabin, en la de Scelsi, así como, en el ámbito de la literatura y por ceñirnos a un territorio hispanohablante, en la poesía de Juan Eduardo Cirlot."

\footnotetext{
${ }^{11}$ Ofrecemos, por su explicitud, los siguientes versos tomados del poemario Bronwyn IV de Juan Eduardo Cirlot, dado que revelan la derogación, en el imaginario del autor, de una cosmovisión trascendente en el sentido aquí explorado, y el engendramiento de otra arraigada a un orden inmanente: "La cruz que, sobre mí, yace sin brazos/abre en sus espirales los momentos/tan ávidos de luz que son cristal”. (Cirlot 152)
} 
Todavía en el ámbito de las letras, resulta de interés acercarnos, en este mismo sentido, al ideario de Georges Bataille, ${ }^{12}$ quien hacia mediados de los años treinta creará una revista -además de una sociedad secreta- de nombre Acéphale, vinculada a un retorno a lo no diferenciador, a lo no asimilable mediante categorías. Se celebra, en otras palabras, la prevalencia de lo no sometido a régimen regulador alguno. ${ }^{13}$ La creencia de Bataille en los cometidos propugnados desde esta sociedad es algo que queda en entredicho, si bien no por ello deja de resultar menos sintomático del fenómeno que vamos comentando, o incluso, justamente por ello, se revela como altamente significativo en tanto que remite al concepto de simulacro. Bataille juega, recordemos, con la idea de llevar a cabo un sacrificio humano, topándonos con ello con la idea de la transferencia simbólica -cuyo mayor exponente en nuestra cultura lo encontramos en la figura de Cristo- en tanto que el sacrificio de un solo sujeto redime -en este caso desde la inversión de valores respecto del modelo de partida- a la colectividad. Simulacro o delirio, el sacrificio, en sentido estricto, no se consumó. Apuntamos, sin entrar en ello, que el concepto de simulacro no necesariamente se identifica con una desacralización estética, sino que puede incluso comprenderse como elemento inherente al rito.

Figura 2.

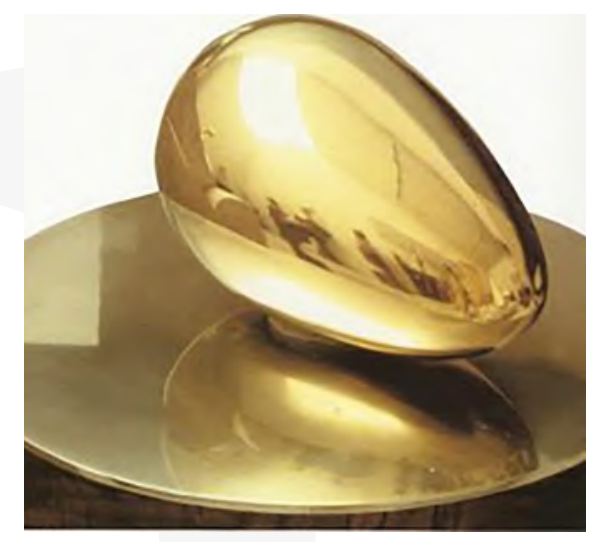

Brancusi, Constantin. Le commencement du monde, 1924. Bronce (tras una versión en mármol de hacia 1920). Centre Pompidou. París.

\footnotetext{
12 Paradigmáticas resultan las palabras expuestas por el autor en aquel primer número de la revista: “La vie humaine est excédée de servir de tête et de raison à l'univers. Dans la mesure où elle devient cette tête et cette raison, dans la mesure où elle devient nécessaire à l'univers, elle accepte un servage" (Bataille 443).

${ }^{13}$ Aspectos que, en la obra de Bataille, hay que poner en relación con sus ideas en torno al materialismo bajo, pero también con la gnosis.
} 
Podemos advertir, prosiguiendo con nuestro discurso, cómo un orden trascendente altamente dañado en sus cimientos a inicios del pasado siglo deja paso a la prevalencia de los dictados del inconsciente. ${ }^{14}$ Esta traslación se explicita, en lo que atañe al imaginario, desde el aludido rechazo al simbolismo de la cruz, así como desde el acogimiento de una serie de símbolos vinculados a una esfera cerrada sobre sí misma. ${ }^{15} \mathrm{El}$ hasta entonces imperante orden eidético de orientación trascendente, ${ }^{16}$ queda sustituido por la prevalencia de un fundamento telúrico, sustancial, explorado por la psicología freudiana $\mathrm{y}$, más adelante -instalados en unos estratos más elementales, colectivos e irracionales-, por la psicología arquetípica y sus posteriores proyecciones -si bien, tal como hoy nos parece, todas ellas no dejan de tener por fundamento inercias racionalizadoras en cierto modo enmascaradas-.

\section{Conforme a esta traslación, encontramos que la cruz que sostenía nuestro ordenamiento simbólico -sobre la que éste coagulaba- viene a derrumbarse. ${ }^{17}$ Orientando todo ello nuevamente hacia el ámbito}

\footnotetext{
${ }^{14}$ Observamos, como puede desprenderse de lo hasta ahora expuesto, en los movimientos organicistas y cobijados en el inconsciente, una respuesta una consecuencia de la derogación de la esfera de valores que hasta el momento cohesionaba nuestra cultura. Creadores o personajes -o una síntesis de amboscomo el propio Bataille y sus descabelladas propuestas, el primer Gide, Genet o Cendrars -con su personaje de Moravagine como prototipo de individuo anómico-, son un fiel exponente de esta deriva. ${ }^{15} \mathrm{Al}$ margen de la relación que esta cuestión guarda con la filosofía de precursores de la moderndad como Spinoza o Leibniz, leemos en la obra de Sloterdijk una comprensión de dicha idea desde su exposición abarcadora y sistemática: "La teoría de la esfera conduce directamente a una reconstrucción morfológica de la onto-teología occidental: en esa doctrina, Dios mismo, fuera lo que fuere en sí y para sí, se conceptualiza como una esfera omniabarcante de la que las doctrinas esotéricas circulantes desde la alta Edad Media afirmarán que su centro está en todas partes y su contorno en ninguna. ¿No fue idéntico en lo profundo de su estructura el proceso de la era moderna a los ensayos de la inteligencia europea para orientarse en esa superesfera inconsciente?" (Sloterdijk 71).

${ }^{16}$ Conforme a la línea de estructuración político-teológica propuesta por Assmann:"Lo que concierne a la historia, la teología y las ciencias de la religión parecen estar de acuerdo con el hecho de que el monoteísmo (entendido como adoración exclusiva de un Dios único y rechazo fundamental de la existencia de otros dioses) salió progresivamente del politeísmo de las primeras religiones orientales pasando por diferentes etapas intermedias, como el henoteísmo (la singularización de un solo Dios más allá de los otros numerosos dioses) y la monolatría (la adoración de un solo Dios reconociendo la existencia de otros dioses). Esta teoría me parece totalmente plausible. Por una parte, se observa, en efecto, que un henoteísmo de contornos relativamente claros se deja ya percibir en las primeras religiones politeístas, que ponen a un solo Dios más alto que a los otros hasta el punto de que todos tienden a disolverse en ese Dios único ('Todos los dioses son uno solo'). Por otra parte, los investigadores de los últimos decenios han mostrado cada vez más claramente que el dios de Israel no era al principio nada más que un jefe de panteón, que superaba muy ampliamente a todos los otros dioses" (45).

${ }^{17}$ No es preciso recurrir a Nietzsche para la exposición de esta idea, en tanto que la fragmentación de una unidad eidética en una polaridad a cada momento más atomizada va a quedar reflejada desde diferentes ámbitos del conocimiento y de forma más o menos explícita con anterioridad a que aquél filosofase a martillazos: podemos recordar a Feuerbach, Stirner o, más lejano en el tiempo, Holbach. Con todo, en esta dialéctica histórica, a cada propuesta deicida le sobreviene
} 
de la estética, observamos cómo el vector estético dominante desde el Renacimiento, vinculado precisamente con una jerarquía de valores que poco después comenzará a deteriorarse -esto es, vinculado con una concreta noción de verdad, de bien y de belleza-, queda en el siglo XX entregado a tantos perspectivismos como aproximaciones a lo real el sujeto es capaz de comprender, crear o simplemente iluminar. Este hecho, nítidamente definido desde los presupuestos teóricos del cubismo y demás movimientos relativistas orientados a destacar la inoperancia o falsedad de un exclusivo punto de vista, dará paso a una exploración y expresión de lo real -de lo que en un momento $\mathrm{u}$ otro tomamos como real- desde un orden sustancial, onírico y arquetípico, es decir, desde todo aquello que, ante todo, engendra. Dicho de otro modo, desde todo aquello que no ofrece cristalizaciones conceptuales pero, sin embargo, las posibilita. El asentamiento de tensiones en un orden sustancial, es sabido, impide antagonismos conceptuales, pero también la definición de un sentido histórico, esto es, de toda noción teleológica. La carga energética de un orden de realidad queda en tales casos acumulada en un estrato telúrico, a la espera de su imprevisible despertar.

El proceso aquí tratado no se va a exponer tan sólo linealmente, aun manteniendo una directriz fundamental -en este caso, la recién mencionada sustitución de la cruz por la esfera-, pues así como la consolidación de una orientación existencial de sentido trascendente convivió en el ámbito occidental por espacio de siglos con reductos más limitados de pervivencia de una cosmovisión inmanente, encontramos recíprocamente en el pasado siglo tendencias opuestas llamadas a dotar de carácter sistémico aquello en apariencia comprendido como irreconciliable. Esto último es, sin ir más lejos, cuanto observamos en los modelos delatores de un monismo trascendental, ${ }^{18}$ tipología eidética conforme a la que se

una respuesta contraria, y así, frente a la evidencia de una pérdida simbólica -contra la que lucharía el romanticismo alemán-, se alza la creencia de Schelling de que el grado alcanzado de fragmentación y disociación precede a una posterior reunificación de presupuestos científicos y presupuestos metafísicos. Esta misma idea es aplicable a nuestra época.

${ }_{18}$ Volviendo a Schelling, Raúl Gabás, en el prólogo a las obras selectas del filósofo, nombra al teólogo Friedrich Christoph Oetinger (1702-1782) -quien a su vez nos lleva hasta Böhme- a la hora de rastrear los referentes de Schelling en su defensa de los vínculos entre trascendencia e inmanencia. Estas ideas perviven, y por momentos se avivan, en la estética del siglo XX, primero con la vuelta a un organicismo elemental y posteriormente en la reunificación de polaridades de sentido resimbolizador afín a nuestra época: "Oetinger, distanciado del dualismo almacuerpo, defendía una corporalidad pneumática. Para él los principios fundamentales eran la vida y el movimiento. Defendía un principio fenomenológico-generativo que atiende a las cosas en la mirada inmediata y en el curso de su nacimiento. Desde su punto de vista, el origen del movimiento es un principio activo e ideal. A través del microscopio, advierte, perdemos de vista lo más importante, a saber, la vida de la naturaleza. Hay un lazo invisible que conecta las fuerzas 
recompone el imaginario contemporáneo. Esta orientación, en líneas generales, es expuesta desde el ámbito de la estética en todos aquellos objetos o imágenes sustentados tanto sobre su materialidad como sobre su idealidad, tal y como podemos advertir, por destacar un gráfico ejemplo, en la obra plástica de Tony Cragg, refiriéndonos con ello a los trabajos pertenecientes a su periodo de madurez. ${ }^{19}$

Figura 3.

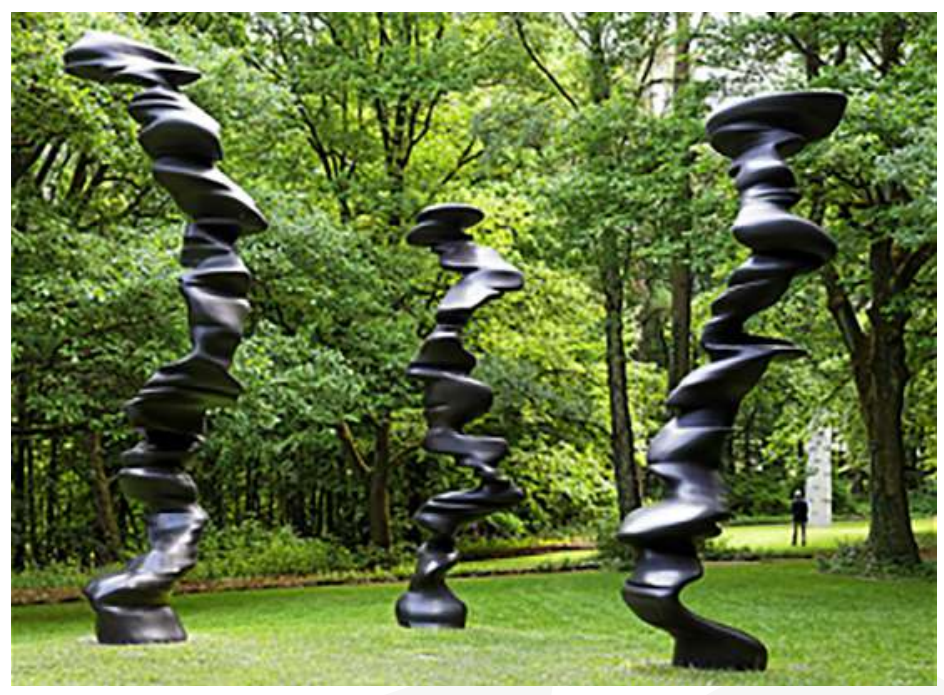

Cragg, Tony. Points of View, (2007). Bronce. Skulpturenpark, Wuppertal.

Llegados a este punto, cabe comprender que la suplantación de un orden eidético por uno sustancial viene, ante todo, a exponer la falta de articulaciones capaces, en un momento dado, de aunar las aparentemente contradictorias aproximaciones a lo que comprendemos como lo real. La nivelación por lo bajo se presenta, visto con perspectiva, como estado natural de todo periodo inicial de renovación de ideas. $\mathrm{Si}$, por una parte, con este giro hacia lo sustantivo nos situamos en la base de un concreto ordenamiento, esto es, en un estrato en que los sedimentos culturales se ven reducidos a su expresión elemental, a su vez sólo desde este necesario grado cero es posible recomponer desde la raíz una imagen del mundo óptima para canalizar tensiones inherentes.

originales, aparentemente en pugna. Oetinger censura a los modernos, que cifran la esencia del alma en la representación y excluyen de ella las fuerzas que implican algo corporal" (Schelling XLI). ${ }^{19} \mathrm{Al}$ respecto, remitimos a: Aguirre-Martínez, Guillermo, "Metamorfosis como fenómeno estético en la escultura de Tony Cragg". Arte, individuo y sociedad 25.2 (2013): pp. 247-259. 


\section{El estado actual}

A lo largo del pasado siglo el sujeto se vio fundamentalmente abocado a participar de niveles en alto grado asimbólicos de existencia, en el sentido de relativos a intuiciones de lo real esquivas a incorporarse a definidas y amplias estructuras eidéticas. Advertido todo ello desde el ámbito de la estética, cabe entender que la convivencia de perspectivas permitió un enriquecimiento de orientaciones proyectadas desde distintos órdenes de la realidad, pero a cambio una imago mundi, para bien o para mal, quedó imposibilitada. Todo ello no derivó en una verdadera cohesión y aceptación de las distintas participaciones de lo real, pues la dominante no dejó de recaer en un componente de indiferenciación. El lazo entre las pluralidades quedó establecido sobre la base de una común organicidad, pero no sobre la de un fenómeno de óptima integración de diferencias conceptuales.

Tras un momento de recomposición y ablución de sentidos de realidad fermentan hoy brotes simbólicos ajustados a nuevas redefiniciones del par inmanencia/trascendencia. Todo ello nos pone frente a frente con un renovado monismo-trascendente. Conviene, ante de concluir, recalcar nuestra comprensión de que todo ordenamiento humano, a poco que se autorregula, deriva en una progresiva estratificación de idealidades. En este aspecto, así mismo, recordamos que si bien una carencia de valores objetivados hunde al individuo en estratos aptos para el surgimiento de todo tipo de propuestas pero no para la consolidación de nuevos sentidos, una hipertrofia de estos últimos, necesariamente, incorpora un principio de enajenación resultante de un exceso de tensiones no articuladas -esto es, incorpora un principio de decadencia-. Todo este curso, según hemos visto, queda evidenciado desde la actividad estética.

Podemos decir, a modo de corolario, que en el arte, como en la vida, un estado de correcta articulación y cohesión se genera en relación con nociones y realidades divergentes si bien conceptualmente integradas, y no ya conforme a su homogeneidad o identidad elemental -siendo precisamente en estos casos cuando lo fragmentado y fragmentario ejerce su prevalencia-. Más allá de ello, y esto resulta algo evidente, la recomposición de un orden simbólico genera en el sujeto tanta ansiedad como expectativas, condición natural del sujeto y, por derivación, de la experiencia estética. 


\section{REFERENCIAS}

Aguirre-Martínez, Guillermo. "Metamorfosis como fenómeno estético en la escultura de Tony Cragg". Arte, individuo y sociedad 25.2 (2013): 247-259. Web. 10 de febrero de 2021.

Assmann, Jan. Violencia y monoteísmo. Barcelona: Fragmenta, 2014. Impreso.

Bataille, Georges. Oeuvres Complètes I. Paris: Gallimard, 1979. Impreso.

Cirlot, Juan Eduardo. Bronwyn IV. Madrid: Siruela, 2001. Impreso.

Gray, John. Liberalism. Minneapolis: University of Minnesota Press, 1986. Impreso. Jaspers, Karl. Origen y meta de la historia. Barcelona: Acantilado, 2017. Impreso. Méndez, Sigmund. "Del Barroco como el ocaso de la concepción alegórica del mundo". Andamios 2.4 (2006): 147-180. Web. 10 de febrero de 2021.

Neumann, Erich. The Archetypal World of Henry Moore. New York: Pantheon Books, 1959. Impreso.

Oteiza, Jorge. Quosque Tandem...! Navarra: Fundación Museo Jorge Oteiza, 2007. Impreso.

Schelling, Friedrich Wilhelm Joseph. Obras selectas. Madrid: Gredos, 2012. Impreso.

Skolimowski, Henryk. La mente participativa. Girona: Atalanta, 2016. Impreso.

Sloterdijk, Peter. Esferas I. Madrid: Siruela, 2009. Impreso.

Trías, Eugenio. La edad del espíritu. Barcelona: Destino, 2000. Impreso.

Wunn, Ina, Las religiones en la Prehistoria. Madrid: Akal, 2012. Impreso.

\section{Como citar:}

Aguirre Martínez, Guillermo. “Consideraciones en torno al proceso de resimbolización en los márgenes de la estética reciente". Discusiones filosóficas. Jul. 21 (37), 2020: https:// doi.org/10.17151/difil.2020.21.37.9 